\title{
Biology, food consumption and control of the gray garden slug deroceras reticulatum
}

\author{
Hend sh. Ghareeb \\ Plant Protection Research Institute, Dokki, Giza, Egypt \\ Corresponding author: hendshokry800@gmail.com
}

\begin{abstract}
Biological, food consumption and control studies were investigated against the gray garden slug, Deroceras reticulatum (Müller) under laboratory conditions. Results show that slugs began egg - laying in early January, and deposited clusters each containing from 21 to 43 oval eggs in or a top the soil. Eggs measured about $2 \mathrm{~mm}$ in length and $3 \mathrm{~mm}$ in width. The transformation being seen through a change of eggs color, from a white color into a pale buff after a week of egg laying. Eggs take from 23 to 27 days to hatch and the hatching period ranged between 6 to 11 days. Hatchability varied between $79 \%$ and $97.3 \%$. Average life span was 55.3 weeks and the post oviposition period recorded about 69.6 days. The mean generation time varied between 50 and 52 weeks. These results indicate that $D$. reticulatum has one generation per year. The amount of leaf tissue consumed per day by adult slugs was more than the other which consumed by juveniles. $0.45,0.28,0.18$ and $0.16 \mathrm{mg}$ were the means of food consumed by juveniles for potato, cabbage, carrots and lettuce, respectively. In case of adults, the highest food consumption was recorded for cabbage by mean $1.14 \mathrm{mg}$ followed by potato, carrots and lettuce by means $0.88,0.40$ and $0.20 \mathrm{mg}$, respectively. Ammonium hydroxide, calcium carbonate, onion juice and potassium chloride were tested against $D$. reticulatum eggs at different dipping periods 10, 20, 30, 40 and 50 seconds. Ammonium hydroxide exhibited the highest effect against eggs by preventing its hatching at the concentration $1.5 \%$ for dipping period 20 seconds. Onion juice gave the same effect at $2 \%$ concentration and 30 seconds dipping period. No hatching occurred also in case of potassium chloride at $1.5 \%$ concentration and dipping period 40 seconds. Calcium carbonate showed the lowest effect against eggs.
\end{abstract}

Keywords: Deroceras reticulatum, biology, food consumption, eggs, Control.

\section{Introduction}

Slugs are known as one of the most important invertebrate pests of agricultural crops. The absence of mechanical disturbance of the soil and the retention of litter, which increases soil moisture, favours slug survival and reproduction (Clemente $\boldsymbol{e t}$ al., 2008). It can feed on a wide range of host plant species. In no - and reduced tillage field crop production, they are considered serious pests of many crop species, including wheat, barley, oats; corn, soybeans, tobacco; canola and other cereals and leguminous forages (Barratt et al., 1994, Cook et al., 1996, Hammond et al., 1999, Barker and Byers 2002). Slugs damage crops by feeding on the seed, resulting in plant mortality before emergence and poor crop stands, and then damage seedlings as plants emerge from the ground (South, 1992). It caused also irregular holes in the plant leaves, roots, tubers and fruits (Genena, 2010). Deroceras reticulatum has now been introduced into most parts of the world, considered the most severe slug species. This species also identified as intermediate hosts of nematode parasites Angiostrongylus costaricensis and A. cantonensis which responsible for abdominal disease angiostrongylosis of humans (South, 1992 and Maurer et al., 2002). It was introduced into Egypt a long time ago, but the biology and ecology of this species in this country are still unknown. On the other hand, the efficient management for any pest requires knowledge of its biology (Barker, 2002). A life cycle pattern is the set of ontogenetic traits that ensures that the products of reproduction are brought into a condition in which they can themselves reproduce. It therefore includes patterns of reproduction (i.e., patterns and rates of growth, frequency of reproduction, and longevity of the parent (Calow, 1983).

The intensity degree of land mollusca feeding has an influence on the amount of damage caused by this mollusca (Godan, 1983). The amount of leaf tissue consumed per day by slug increased with size (age). The relative consumption rate $\left(\mathrm{cm}^{2} /\right.$ day) declined with age throughout development (John and Cleiton, 2015). Slugs are challenging to control because of the limited number of management tactics that are available (Rice and Steffey, 2012). Search for eggs masses and destroy them represents one of the control methods. The aims of this study were to illustrate the reproduction or life history, growth rate and survival of $D$. reticulatum, and also to determine the food consumption of juveniles and adults. The study also extends to assess effects of the compounds; ammonium hydroxide, calcium carbonate, onion juice (Allium cepa) and potassium chloride on eggs of this slug species at different dipping periods.

\section{Materials and Methods}

Collection and rearing of slugs 
Adults of Deroceras reticulatum were collected on 27 October 2013 from infested cabbage in Inshas, Belbies district, Sharkia Governorate, Egypt. Slugs were placed on moist clay soil in plastic boxes (23 $\mathrm{cm} \times 23 \mathrm{~cm} \times 12 \mathrm{~cm}$ ) with holes made in the lid, allowing air circulation whilst ensuring a moist atmosphere. The rearing boxes were supplied daily with fresh cabbage leaves. The slugs were allowed to acclimatize to the laboratory condition for suitable period before any test (Clemente et al., 2008). Egg laying was observed each day and all egg clutches deposited in the rearing boxes were carefully collected for the following experiments.

\section{Reproduction experiment}

On 7 November, 25 round plastic boxes $(13 \mathrm{~cm}$ diameter) with holes for allowing air circulation were prepared. Each box contained $1 / 2 \mathrm{Kg}$ moistened clay soil. Adult slugs were paired and each pair was put into each box. The boxes were examined daily for observe the egg laying. Each box also provided with fresh cabbage leaves and remoistened as required each day (Ali, 2011). The time of oviposition was recorded and number of clutches which laid in each box were counted (Godan, 1983). Eggs of each clutch were counted also and then transferred to the new boxes which prepared as the parent boxes and put at the same depth of oviposition. The egg clutches were examined daily to observe the changing of eggs color from the time of laying till hatching. The incubation period (the period from egg laying to the first egg hatching), hatching period (the period from first egg hatching to the last hatching egg of each clutch) and hatchability (\% of eggs hatched) were recorded. The juveniles were supplied daily with fresh cabbage leaves and soil remoistened until it reached to maturity and completes their life span. Juveniles length was measured at the off spring stage (newly hatched slug) and 2, 4, 6 and 9 months age. The oviposition period (from the beginning of first laying until the date of the last egg laid by adult slug), fecundity (number of eggs / slug), number of eggs per clutch, life span (from hatching slug till its mortality), post oviposition period (the period elapsed from the last deposited egg till death of animals) and the generation period (from egg to egg) were also determined.

\section{Food consumption}

The food consumption of slug juveniles and adults for some plant leaves and tubers was tested separately under the laboratory conditions. From the rearing boxes, the deposited eggs were transferred to other boxes contained moistened clay soil. These boxes divided into two groups which examined daily to determine the hatching date under the laboratory conditions. The first group includes eggs give small individuals was reared until become have 4 months. The second group includes eggs give small individuals reared until reached adults have 10 months.

25 juveniles (4 months) age were divided into 5 replicates, each one containing five juveniles in plastic boxes (3/4 kg capacity). Clay soil was placed in the boxes and soil moisture was adjusted. One disc of each food type; cabbage (Brassica oleracea), carrots (Daucus carota), lettuce (Lactuca sativa) and potato (Solanum tuberosum) was offered to juveniles in each replicate. Discs weighted daily before and after application during 3 successive days (Ismail $\boldsymbol{e t}$ al., 2010). Aliquot of food was kept in the same conditions to calibrate the water lost from the food provided. The same experiment repeated with its details with the adult slugs (10 months) for determine the food consumed by adults at this age against the same four plant species mentioned before.

\section{Ovicidal effect}

The toxic effect of some mineral salts and onion extract i.e. ammonium hydroxide $\mathrm{NH} 4 \mathrm{OH}$ (33\%), calcium carbonate $\mathrm{CaCO} 3(98 \%)$, onion juice and potassium chloride KCL (99\%) were tested against $D$. reticulatum eggs by dipping technique under the laboratory conditions. The three chemical compounds were obtained from El-Gomhouria Company, Egypt. But the onion juice was prepared by collected onion bulb from the field, removed peels then it weighted about 200 grams of onion bulbs then grinding it by electric grinder. The yield was filtrated by using muslin cloth to obtain clear juice. The filtrate onion juice was kept in refrigerator until using (Zaki, 2013). Four concentrations 0.5, 1.0, 1.5 and $2.0 \%$ from each compound were prepared by solving the amount of each tested compound required to obtain the appropriate concentration in water (Mahmoud, 1994). Suitable number of eggs which laid in the rearing boxes were collected by a fine hair brush and dipped in each compound concentration at different dipping periods $10,20,30,40$ and 50 seconds. This dipping process occurred by using a piece of white cloth and then transferred to the boxes at the same depth of eggs laying. Three replicates were prepared for each concentration and other three boxes prepared as a control (eggs dipped in distilled water only). The boxes were covered with muslin cloth and secured with rubber band for protection. All boxes examined daily for calculate the hatching percentage (Shokry, 2013).

\section{Results and Discussion}

Classification

The slug classified according to Godan (1983) as follows:-

Kingdom: Animalia

Subkingdom: Metazoa

Phylum: Mollusca

Class: Gastropoda

Subclass: Pulmonata 
Order: Stylommatophora

Subfamily: Daudebardiinae

Family: Limacidae

Genus: Deroceras

Species: Deroceras reticulatum

\section{Description}

According to Douglas and Tooker (2012)

Deroceras reticulatum slug color ranging from cream colored with irregular gray spots to dark brown with dark spots and the skin is thick. The gray garden slug produces sticky, white mucus when disturbed (an identifying characteristic of this species). It often has a mottled appearance. It's length is about $5 \mathrm{~cm}$ (2 in.) long when fully grown. The mantle is situated forward, near the head, and the respiratory pore is behind the mid-point of the mantle. The keel is located only at the tail (Figure 1).
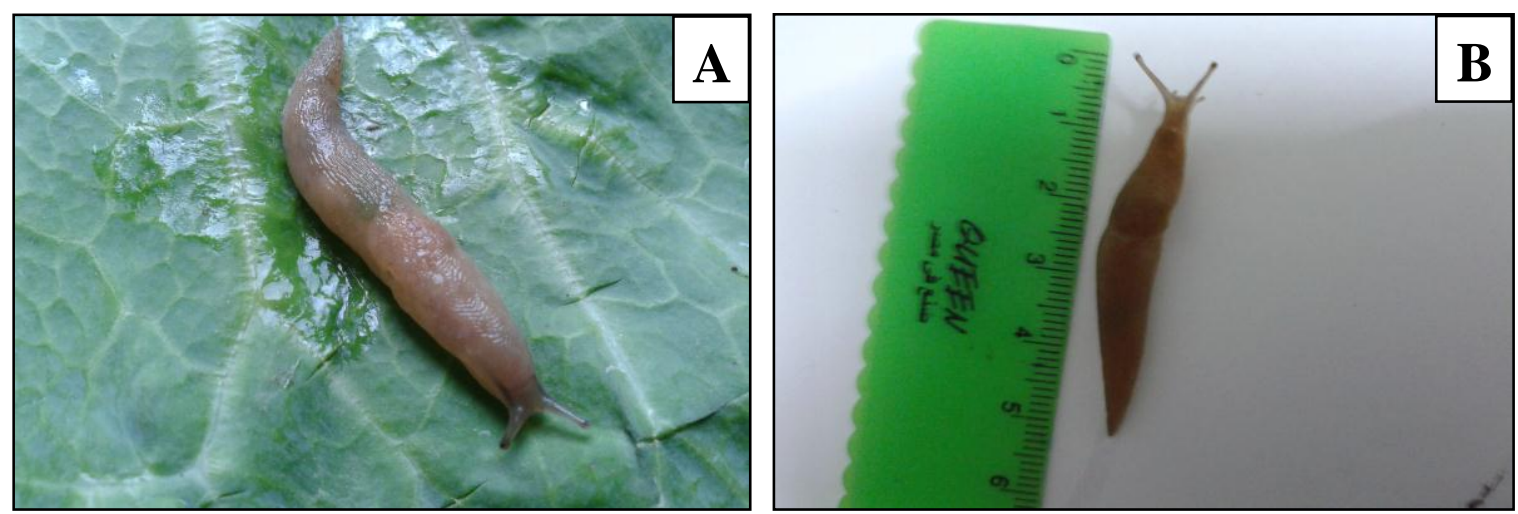

Fig. (1 A, B): Description of Deroceras reticulatum slug. A, view of the slug external features on cabbage leaf. B, length of the fully grown individual.

Life cycle

As cleared in Figure (2) and Table (1), D.

white oval eggs. The egg average diameter was 3 reticulatum laid a small and translucent or pearly $\mathrm{mm}$ and it's length was about $2 \mathrm{~mm}$.
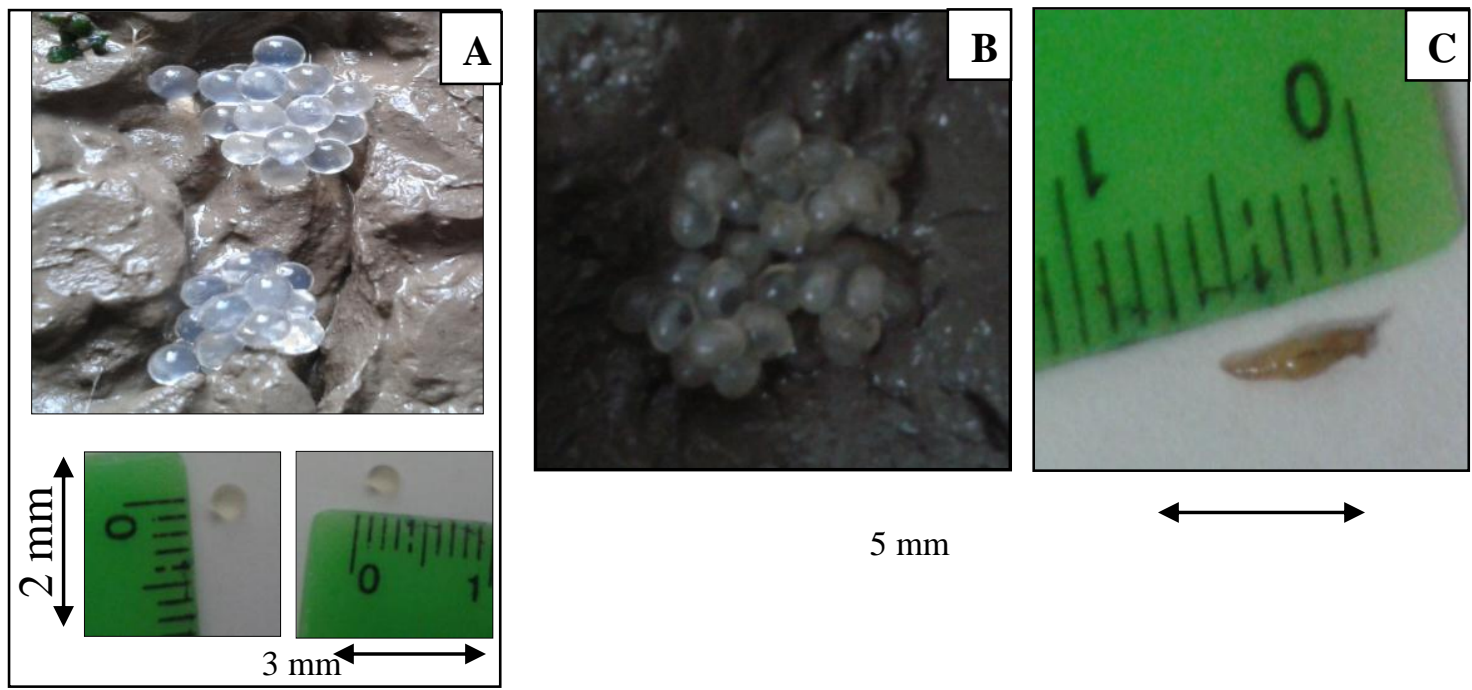

$5 \mathrm{~mm}$
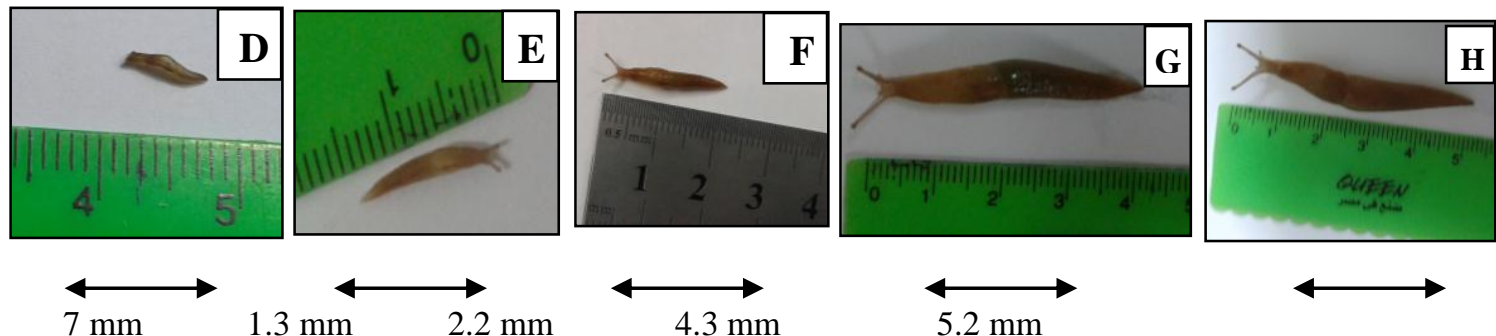

$4.3 \mathrm{~mm}$

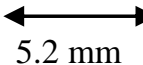

Fig. (2 A - H): Life cycle of Deroceras reticulatum slug. A, New deposited eggs. B, Eggs after one week. C, Newly hatched slug. D, Slug at 2 months. E, Slug at 4 months. F, Slug at 6 months. G, 9 months age slug. H, Fully grown individual. 
These results in harmony with Kim et al. (2009) indicated that the egg size of $D$. reticulatum was $1.91 \times 2.19 \mathrm{~mm}$. While, Fromming (1954) recorded that the egg size of Limax maximus, Lehmannia marginata, Deroceras laeve and Arion intermedius was $6 \times 4.5 \mathrm{~mm}, 5 \times 4 \mathrm{~mm}, 2.8 \mathrm{~mm}$ and $3.1 \times 2.5$ $\mathrm{mm}$, respectively. After one week of laying eggs the eggs color changed to a pale buff. The incubation period ranged from 23 to 27 days with an average $24.7 \pm 1.0$ days. But 8.4 days was the mean of the hatching period. The hatchability ranged from 79 to $97.3 \%$ with an average of $88.3 \pm 2.3 \%$. The newly hatched $D$. reticulatum were light brown with a mean length of $5 \mathrm{~mm}$. It's length was increased by increasing age reached to $7 \mathrm{~mm}$. at 2 months. 1.3 , $2.2,4.3 \mathrm{~cm}$ were the lengths of juveniles at 4, 6 and 9 months, respectively. D. reticulatum reached to 5.2 $\mathrm{cm}$ long when fully grown. The obtained results were consistent with the data of Clemente et al. (2008) found that the incubation period of $D$. reticulatum eggs was 25.9 days and the hatchability ranged between 83.9 to $91.1 \%$. The newly hatched of $D$. reticulatum has a light brown color with a mean length $3.8 \mathrm{~mm}$. On the same trend, Ali (2011) estimated that the range of incubation period in case of $D$. laeve eggs was from 17 to 21 days, the hatching period recorded few days (from two to six days). The hatchability ranged between 28 to $100 \%$ with an average of $79.2 \pm 20.0 \%$.

In the current study, the number of eggs per clutch ranged between 21 and 43 eggs with average $32.33 \pm$ 4.1. The mean of fecundity (eggs/slug) was 67.3 eggs throughout the season, but the generation time recorded 51.3 weeks it means that $D$. reticulatum has one generation per year. 32.6 days was the mean of oviposition period while, the post oviposition period recorded 69.6 days. The life span (longevity) was varied between 54 and 57 weeks. In this research the low fecundity of $D$. reticulatum 65 to 70 eggs/slug, appears to be unusual for this species. For example Branson (1980) recorded that $D$. reticulatum deposited from 60 to 75 eggs and these results are nearly agree with our results. On the other hand, Carrick (1938 in South 1982), stated that $D$. reticulatum laid up to 500 eggs in a year, and South (1982) reported that mean number of eggs/slug was 205.

Table 1. Meanstandard error of the life history parameters of Deroceras reticulatum.

\begin{tabular}{|c|c|c|c|c|c|c|c|c|c|}
\hline Items & 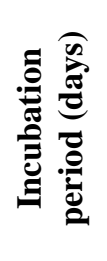 & 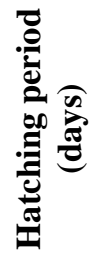 & 苞 & 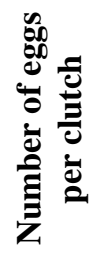 & 氖兽 & 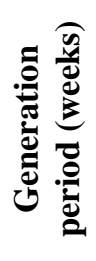 & 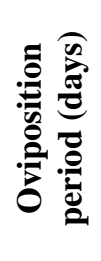 & 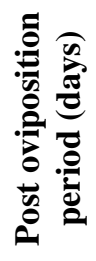 & 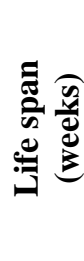 \\
\hline Average & 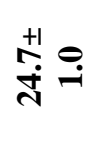 & $\begin{array}{l}0 \\
0 \\
+1 \\
+\infty\end{array}$ & $\begin{array}{l}+1 \\
\stackrel{+}{\infty} \\
\infty\end{array}$ & 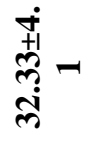 & $\stackrel{+1}{n} \underset{0}{+}$ & $\underset{n}{+1} \underset{n}{n}$ & $\begin{array}{l}+1 \\
\underset{0}{+} \\
\text { ஸे }\end{array}$ & $\begin{array}{l}+1 \\
\dot{0} \\
\hat{\sigma}\end{array}$ & ڤ̊ \\
\hline Range & $\begin{array}{l}\hat{N} \\
\ddot{1}\end{array}$ & $\overrightarrow{7}$ & $\begin{array}{l}\frac{m}{a} \\
a \\
\mathfrak{n}\end{array}$ & $\begin{array}{l}\dddot{m} \\
\dot{7}\end{array}$ & $\begin{array}{l}R \\
18\end{array}$ & $\begin{array}{l}1 \\
\text { in } \\
\text { है }\end{array}$ & $\begin{array}{l}\text { ले } \\
\text { ले }\end{array}$ & $\begin{array}{l}\bar{\infty} \\
\dot{8}\end{array}$ & $\begin{array}{l}\text { in } \\
\text { in }\end{array}$ \\
\hline
\end{tabular}

The same author added that the life cycle of $D$. reticulatum has three phases: an initial phase of rapid growth followed by a phase of slow growth during which slugs lay eggs and, finally a phase of little or no growth. The results which obtained by Alford (1984) were supportive to our findings about the generation period, indicated that it was often extend to about year in case of $D$. reticulatum. While, Barker (1991) observed two generations of $D$. reticulatum in 1 year, one in autumn and another in spring, with intervals between consecutive generations of 4 to 7 months. Nickles and Hoffmann (1981) cleared that the minimum generation time of $D$. laeve was six weeks. On the other hand, Godan (1983) published that oviposition in $D$. reticulatum took place 8 to 10 days after copulation, in Arion rufus (L.) only after several weeks. $33.3 \pm 7.6$ days and $20.9 \pm 10.3$ days were the post-oviposition period of $D$. laeve and L. flavus, respectively (Ali, 2011). About the life span, our results are strongly agree with those which illustrated by Inagaki (1972) showed that the life span of $D$. reticulatum was 9 to 13 months. Added that Limacidae are generally longer lived than the Arionidae. Faberi et al. (2006) cited that $21.9 \pm 5.1$ weeks was the average of life span in case of $D$. laeve.

\section{Food consumption}


Data in Table (2) showed that the juveniles consumed more amount of food during the first day comparing with the rest period of experiment except in case of potato; the highest consumption was recorded at the second day. The highest mean of food consumption was recorded for potato with $0.45 \mathrm{mg}$. It followed by cabbage, carrots and lettuce with 0.28 , 0.18 and $0.16 \mathrm{mg}$ consumption, respectively.

Table 2. Food consumption of Deroceras reticulatum juveniles and adults against some plants.

\begin{tabular}{|c|c|c|c|c|c|c|c|c|}
\hline \multirow{3}{*}{ Plants } & \multicolumn{4}{|c|}{ Juveniles } & \multicolumn{4}{|c|}{ Adults } \\
\hline & \multicolumn{8}{|c|}{ Food consumed (mg) at indicated days } \\
\hline & $1^{\text {st }}$ & $2^{\text {nd }}$ & $3^{\text {rd }}$ & Mean & $1^{\text {st }}$ & $2^{\text {nd }}$ & $3^{\text {rd }}$ & Mean \\
\hline Cabbage & $0.36^{\mathrm{b}}$ & $0.29^{b}$ & $0.19^{\mathrm{b}}$ & $0.28^{\mathrm{b}}$ & $0.57^{\mathrm{b}}$ & $1.49^{\mathrm{a}}$ & $1.38^{\mathrm{a}}$ & $1.14^{\mathrm{a}}$ \\
\hline Carrots & $0.29^{\mathrm{c}}$ & $0.18^{\mathrm{c}}$ & $0.08^{\mathrm{c}}$ & $0.18^{c}$ & $0.36^{\mathrm{c}}$ & $0.68^{c}$ & $0.16^{\mathrm{c}}$ & $0.40^{\mathrm{c}}$ \\
\hline Lettuce & $0.27^{\mathrm{c}}$ & $0.17^{\mathrm{c}}$ & $0.05^{\mathrm{c}}$ & $0.16^{\mathrm{c}}$ & $0.31^{\mathrm{d}}$ & $0.22^{\mathrm{d}}$ & $0.09^{\mathrm{c}}$ & $0.20^{\mathrm{d}}$ \\
\hline Potato & $0.46^{\mathrm{a}}$ & $0.62^{\mathrm{a}}$ & $0.27^{\mathrm{a}}$ & $0.45^{\mathrm{a}}$ & $0.79^{\mathrm{a}}$ & $1.20^{\mathrm{b}}$ & $0.66^{\mathrm{b}}$ & $0.88^{\mathrm{b}}$ \\
\hline L.S.D 0.05 & $0.036^{* * *}$ & $0.048^{* * *}$ & $0.047^{* * *}$ & $0.033^{* * *}$ & $0.038^{* * *}$ & $0.196^{* * *}$ & $0.073^{* * *}$ & $0.057^{* * *}$ \\
\hline
\end{tabular}

That is no significant differences between the food intakes by juveniles for carrots and lettuce. On the other hand, adults consumed the highest amount of food at the second day except in case of lettuce which showed the highest consumption at the first day of experiment. 1.14. $0.88,0.40$ and $0.20 \mathrm{mg}$ were the means of food consumed by adult individuals against cabbage, potato, carrots and lettuce, respectively. Generally, the amount of leaf tissue consumed per day by adult slugs was more than the other which consumed by juveniles (i.e) the relative consumption rate increased with age. The mean of adults food consumption was significantly higher ( $\mathrm{P}$ $<0.05)$ in case of cabbage than the other plants. Godan (1983) cited that the quantity of plant material consumed by slug is very considerable. Thus, an adult Arion rufus ate in one day $2 \mathrm{~g}$ lettuce, $4 \mathrm{~g}$ tomatoes. 4 to $5 \mathrm{~g}$ cucumber or up to $6 \mathrm{~g}$ pumpkin. While, Deroceras reticulatum ate the equivalent of a quarter of its own body weight $(2 \mathrm{~g})$.
The quantity of lettuce which consumed by the adults of $D$. reticulatum, D. laeve, A. hortensis and Milax sowerbyi were 200, 165, 95 and $366 \mathrm{mg}$, respectively. $D$. reticulatum is one of the most commonly occurring mollusks with agronomic importance consuming up to $80 \%$ of the leaf surface of raps (Gonzalez-Cruz and San-Martin, 2013). At the same trend, Kim et al. (2012) illustrated that $D$. reticulatum caused the highest damage against Chinese cabbage, followed by cucumber and significantly low on beet, kale and carrots. While, Kozlowski (2012) showed that D. reticulatum caused a high level of damage in the crops: potato, beet root, brassicas and root plants.

\section{Ovicidal effect}

Results in Table (3) indicated that the hatchability of Deroceras reticulatum eggs decreased by increasing the dipping periods in the all tested compounds.

Table 3. Effect of some compounds on egg hatchability \% of Deroceras reticulatum.

\begin{tabular}{|c|c|c|c|c|c|c|}
\hline \multirow{2}{*}{ Treatments } & \multirow{2}{*}{$\begin{array}{c}\text { Conc. } \\
(\%)\end{array}$} & \multicolumn{5}{|c|}{ (Mean \pm SE) of hatchability $\%$ at dipping periods (Sec.) } \\
\hline & & 10 & 20 & 30 & 40 & 50 \\
\hline \multirow{4}{*}{$\begin{array}{l}\text { Ammonium } \\
\text { hydroxide }\end{array}$} & 0.5 & $13.15 \pm 1.06$ & $10.71 \pm 1.17$ & 0 & 0 & 0 \\
\hline & 1.0 & $11.42 \pm 1.11$ & $5.26 \pm 0.68$ & 0 & 0 & 0 \\
\hline & 1.5 & $6.50 \pm 0.5$ & 0 & 0 & 0 & 0 \\
\hline & 2.0 & $2.56 \pm 1.33$ & 0 & 0 & 0 & 0 \\
\hline \multirow{4}{*}{$\begin{array}{l}\text { Calcium } \\
\text { carbonate }\end{array}$} & 0.5 & $84.03 \pm 2.21$ & $78.33 \pm 1.15$ & $70.00 \pm 1.66$ & $64.56 \pm 1.41$ & $31.25 \pm 1.69$ \\
\hline & 1.0 & $77.00 \pm 1.18$ & $69.50 \pm 0.86$ & $61.53 \pm 1.54$ & $50.00 \pm 1.12$ & $24.32 \pm 2.60$ \\
\hline & 1.5 & $63.11 \pm 1.83$ & $52.12 \pm 1.77$ & $40.00 \pm 2.96$ & $30.76 \pm 1.17$ & $17.64 \pm 1.74$ \\
\hline & 2.0 & $56.24 \pm 1.42$ & $41.28 \pm 1.24$ & $26.92 \pm 0.47$ & $13.63 \pm 1.79$ & $5.88 \pm 0.80$ \\
\hline \multirow{4}{*}{ Onion juice } & 0.5 & $69.23 \pm 0.90$ & $52.63 \pm 1.04$ & $41.66 \pm 1.20$ & $25.00 \pm 1.05$ & 0 \\
\hline & 1.0 & $55.88 \pm 2.12$ & $33.33 \pm 1.45$ & $29.41 \pm 1.44$ & $17.85 \pm 1.60$ & 0 \\
\hline & 1.5 & $34.78 \pm 1.27$ & $20.00 \pm 2.0$ & $12.50 \pm 0.75$ & 0 & 0 \\
\hline & 2.0 & $21.42 \pm 1.68$ & $13.66 \pm 0.95$ & 0 & 0 & 0 \\
\hline \multirow{4}{*}{$\begin{array}{l}\text { Potassium } \\
\text { chloride }\end{array}$} & 0.5 & $71.79 \pm 1.17$ & $58.61 \pm 2.21$ & $30.55 \pm 1.28$ & $25.00 \pm 1.32$ & 0 \\
\hline & 1.0 & $56.41 \pm 1.75$ & $44.18 \pm 1.51$ & $22.72 \pm 0.89$ & $7.69 \pm 1.80$ & 0 \\
\hline & 1.5 & $48.70 \pm 1.82$ & $36.84 \pm 1.57$ & $14.28 \pm 1.39$ & 0 & 0 \\
\hline & 2.0 & $35.89 \pm 1.44$ & $28.94 \pm 1.73$ & $9.52 \pm 0.75$ & 0 & 0 \\
\hline
\end{tabular}


Ammonium hydroxide exhibited the highest effect against eggs prevented it's hatching at 1.5 and $2 \%$ concentrations when dipping occurred for 20 seconds. Followed by onion juice which achieved the same effect at the concentration $2 \%$ for dipping period 30 seconds. Potassium chloride gave zero hatchability also at 1.5 and $2 \%$ concentrations at dipping 40 seconds. Calcium carbonate recorded the lowest effect against eggs, 5.88\% hatchability represent the highest effect exhibited by this compound at the highest concentration $2 \%$ for dipping period 50 seconds. These results were supported by Dankowska (2009) reported that the traditional molluscicides in greenhouses conditions are not always effective against slugs, hence new chemicals and ways of their application are sought. Severalnon molluscicide proved to be of little effectivity against Deroceras laeve eggs when it was below $30 \%$ but oncol 120EC decreased hatching success by $60 \%$. Cupric sulphate, aluminium sulphate, ferric chloride and zinc sulphate were a highly effective against $D$. reticulatum eggs after four days of exposure (Iglesias et al., 2000). At the same side, Iglesias et al. (2002) cleared that the compounds such as carvone, iron-EDDHA, saponin and an extract of Pongamia pinnata killed the eggs of $D$. reticulatum after periods of exposure ranging from 2 to 14 days. Shokry (2013) stated that ammonium nitrate and urea recorded 55.74 and $58.08 \%$ hatchability of Monacha cartusiana eggs when tested at $2 \%$ concentration for dipping period 10 seconds. Copper - impregnated mattings, copper foil, urea formaldehyde, cinnamamide and garlic concentrates proved to be most effective at reducing D. reticulatum damage (Schuder et al., 2002).

\section{References}

Alford, D. V. (1984). A colour atlas of fruit pests their recognition, biology and control. A Wolfe Science Book, 320 p.

Ali, R. F. (2011). Studies on some gastropods. Ph. D. Thesis, Fac. of Agriculture, Cairo Univ., 133 pp.

Barker, G. M. (1991). Biology of slugs (Agriolimacidae and Arionidae : Mollusca) in New Zealand hill country pastures. Oecologia, 85 : 581- 595.

Barker, G. M. (2002). Vaginulidae in Central America, with emphasis on the bean slug Sarasinula plebeian. In : Molluscs as Crop pests, G. M. Barker (ed.), London, CABI, PP. 115-145.

Barker, G. M. and Byers, R. A. (2002). Agriolimacidae and Arionidae as pests in Lucerne and other legumes in forage systems of North-Eastern

North America, pp. 325-335. In Barker GM (ed.) Molluscs as crop pests. CAB International, Wallingford, United Kingdom.
Barratt, B. I.; Byers, R. A. and Bierlein, D. L. (1994). Conservation tillage crop yields in relation to grey garden slug [Deroceras reticulatum (Müller)] (Mollusca: Agriolimacidae) density during establishment. Crop Protection, 13: 49-52.

Branson, B. A. (1980). The recent gastropoda of Oklahoma, Part VIII. The slug families Limicidae, Arionidae, Veronicellidae, and Philomycidae. Proc. Okla. Acad. Sci., 60: 29-35.

Calow, P. (1983). Life cycle patterns and evolution. The Mollusca Ecology, 6: 649-678.

Clemente, N. L.; Lopez, A. N.; Monterubbianesi, M. G.; Gazzaniga, N. J. and Manetti, P. L. (2008). Biological studies and phonology of the slug Deroceras reticulatum (Müller, 1774) (Pulmonata : Stylommatophora). Invert. Reprod. and Develop., 52 (1-2) : 23-30.

Cook, R. T.; Bailey S. E. and Mc Crohan C. R. (1996). Slug preference for winter wheat cultivars and common agricultural weeds. J. Appl. Ecol., $33: 866-872$.

Dankowska, E. (2009). Effectivity of selected nonmolluscicide chemicals against the slug Deroceras laeve (O. F. Muller, 1774) (Gastropoda, Pulmonata, Limacidae). Folia Malacologica, 17 (4) : 215-217.

Douglas, M. R. and Tooker, J. F. (2012). Slug (Mollusca : Agriolimacidae, Arionidae) ecology and management in no-till field crops, with an emphasis on the mid-Atlantic region. J. of Integ. Pest Manag., 3 (1) : 1-9.

Faberi, A. J.; Lopez, A. N.; Manetti, P. L.; Clemente, N. L. and Alvares, M. A. (2006). Growth and reproduction of the slug Deroceras Laeve (Müller) (Pulmonata : Stylommatophora) under controlled conditions. Spanish J. of Agric. Res., 4 (4) : 345-350.

Frömming, E. (1954). Biologie der Mitteleuropäischen landgastropoden. Duncker \& Humblot, Berlin.

Genena, M. (2010). Biological control of land snails and slugs. Controlling of land snails and slugs Book, $100 \mathrm{pp}$.

Godan, D. (1983). Pest slugs and snails, biology and control. Springer Verlag, Berlin Heidelberg. 445 pp.

Gonzalez-Cruz, D. and San Martin, R. (2013). Molluscicidal effects of saponin - rich plant extracts on the grey field slug. Cienciae Investigacion Agraria, 40 (2) : 341-349.

Hammond, R.; Beck, T.; Smith, J.; Amos R.; Barker, J.; Moore, R.; Siegrist, H.; States D. and Ward B. (1999). Slugs in conservation tillage corn and soybeans in the eastern corn Belt. J. Entomol. Sci., 34 : 467-478.

Iglesias, J.; Castillejo, J.; Parama, R.; Mascato, R. and Lombardia, M. (2000). Susceptibility of the eggs of the pest slug Deroceras reticulatum to 
contact with metal salts. J. of Moll. Stud., 66 (2) : 171-176.

Iglesias, J.; Castillejo, J.; Ester, A.; Castro, R. and Lombardia, M. (2002). Susceptibility of the eggs of the field slug Deroceras reticulatum to contact with pesticides and substances of biological origin on artificial soil. Annals of Appl. Biol., 140 (1): 53-59.

Inagaki, H. (1972). Senescence dans la croissance chez le male de Littorina saxatilis Var. rufus (Olivi), Mollusque Gasteropode, mise en evidence par la regression sexuelle et la diminution de lintensite respiratoire. C. R. Hebd. Séance Acad. Sci. Ser. D. Sci. Nat., 274: 18281831.

Ismail, Sh. A.; Shetaia, S. Z. and Samah, M. A. (2010). Effect of neem extract, neemazal on two land snail species under laboratory conditions. J. Plant Prot. and Path., Mansoura Univ., 1 (10): 799-806.

John, L. and Cleiton, G. (2015). Biology and control of the leather leaf slug Leidyula floridana (Mollusca: Gastropoda : Veronicellidae). Florida Entomolog. J., 98 (1): 243-235.

Kim, H.; Bae, S.; Lee, G.; Yoon, Y.; Park, S.; Choi, B. and Park, C. (2009). Effects of temperature on the development and longevity of the gray field slug, Deroceras reticulatum Muller (Stylommatophora : Limacidae). Korean J. of Appl. Entomol., 48 (4) : 541-546.

Kim, H.; Bae, S.; Yoon, Y.; Choi, B. and Park, C. (2012). Host preference of gray field slug, Deroceras reticulatum Muller, and its development and longevity on host plants. Korean J. of Appl. Entomol., 51 (1): 33-37.

Kozlowski, J. (2012). Slugs as an example of a new and growing threat to crops in Poland. Progress in Plant Protection, 52 (4): 1129-1135.

Mahmoud, M. F. (1994). Ecological, biological and toxicological studies on land snails. M. Sc. Thesis, Fac. Agric. Cairo Univ., 129 pp.

Maurer, R.; Graeff-Teixeira, C.; Thome, J.; Chiaradia, L.; Sugaya, H. and Yoshimura, K. (2002). Natural infection of Deroceras laeve (Mollusca : Gastropoda) with metastrongylid larvae in a transmission focus of abdominal angiostrongyliasis. Revista Instituto Medicina Tropical Sao Paulo, 44 (1) : 53-54.

Nicklas, N. L. and Hoffmann, R. J. (1981). A pomictic parthenogensis in a hermaphroditic terrestrial slug, Deroceras laeve (Müller). Biol. Bull., 160: 123-135.

Ribadulla, P.; Iglesias, J.; Castillejo, J. and Cordoba, M. (2011). Food consumption and activity in Deroceras reticulatum and Cantareus aspersus. IOBC / WPRS Bulletin, 64: 199-205.

Rice, M. E. and Steffey, P. L. (2012). Slug (Mollusca : Agriolimacidae : Arionidae) Ecology and management in no-till field crops, with an emphasis on the mid-Atlantic region. J. of Integ. Pest Manag., 3 (1) : 1-9.

Schuder, I.; Port, G. and Bennison, J. (2002). Novel pesticides for slug and snail control in horticulture. The BCPC Conference: Pests and diseases, Volumes 1 and 2. Proceedings of an international conference held at the Brighton Hilton Metropole Hotel, Brighton, UK, 18-21 November 2002: 873-878.

Shokry, H. Gh. (2013). Efficiency of some biological and chemical compounds and their combinations for control some land snails. Ph. D. Thesis, Fac. of Science, Benha Univ., 282 pp.

South, A. (1982). A comparison of the life cycles of Deroceras reticulatum (Müller) and Arion intermedius Normand (Pulmonata : Stylommatophora) at different temperatures under laboratory conditions. J. Moll. Studies, 48 : 233-244.

South, A. (1992). Terrestrial slugs. Biology, Ecology and Control. Chapman and Hall, New York.

Waldbauer, G. P. (1964). The consumption, digestion and utilization of solanaceous and nonsolanaceous plants by larvae of the tobacco hornworm, Procoparce sexta (Johan.) (Lep. Sphingidae). Ent. Exp. and Appl. 7 : 253-269.

Zaki, W. A. (2013). Chemical and biological studies on the effect of some plant extracts on spiny bollworm, Earias insulana (Boisd.). M. Sc. Thesis, Fac. of Science, Zagazig Univ., 135 pp. 


\section{بيولوجي و الإستهلاك الظذائي و مكافحه بزاقه الدائق الرمادي}

ديروسيراس ريتيكيولالتم

$$
\text { معهد بحوث وقايه النباتات - الدقي - جيزه - مصر }
$$

أجريت الدراسه بهدف التعرف على السلوك البيولوجي و الإنتهلاك الغذائي و كيفيه مكافحه بزاقه الحدائق الرمادي ديروسيراس ريتيكيولاتم تحت

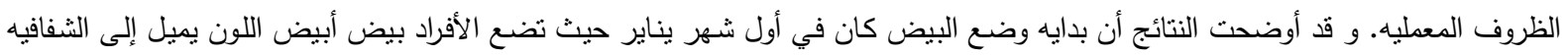

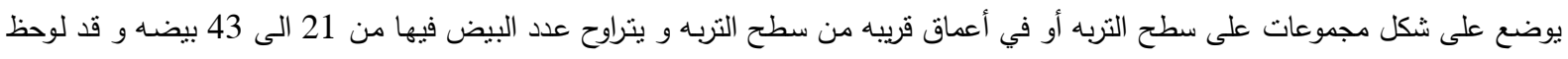

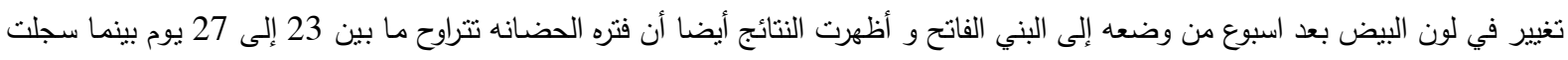

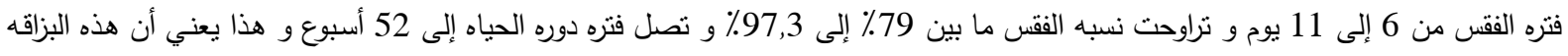

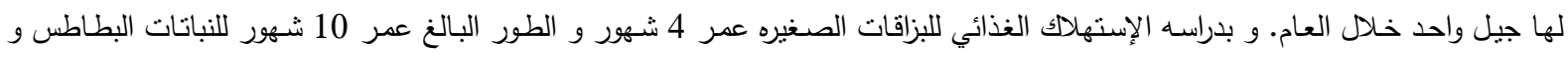

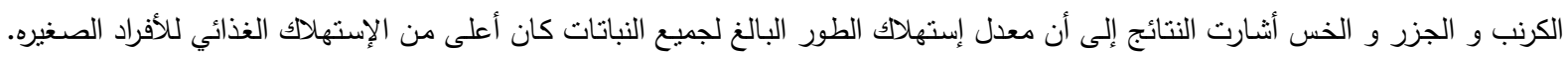

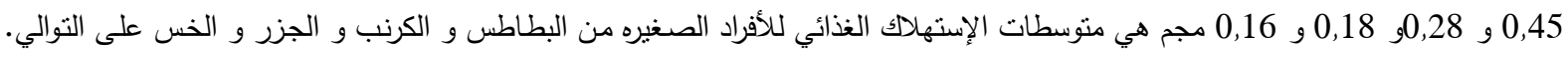

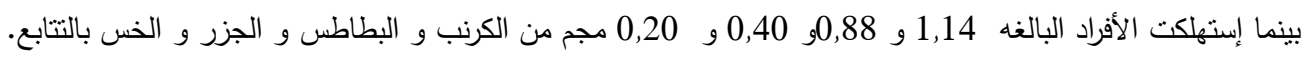

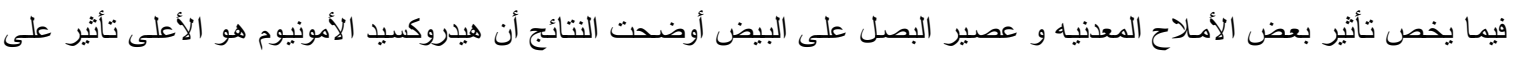

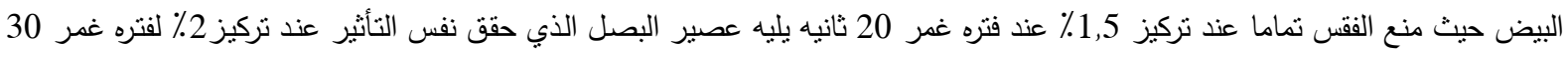

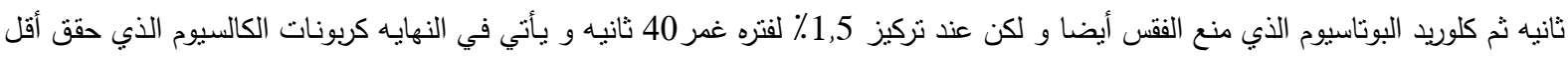
نأثير على البيض حيث سجل نسبه فقس 5,88٪ عند أعلى تركيز 2\% لأطول فتره غمر 50 ثانيه. 